\title{
YOGA ASANAS SEBAGAI PENUNJANG KONSENTRASI BELAJAR SISWA
}

Oleh:

\author{
Ni Putu Erlina Partini \\ Guru Yoga dan Agama Hindu di SD Bali Public School
}

Email: erlinapartini@gmail.com

\begin{abstract}
:
The concentration of learning plays an important role in the learning process. However, with the development of Science and Technology at this time, the concentration of student learning is not necessarily owned by students. Concentration of mind is a state of learning that requires calm, comfort, someone's attention in understanding the content of the lesson faced. When a student is not able to focus on the lesson being obtained, students will not be able to concentrate, so students will experience forgetfulness in the subjects being obtained. One training that is considered capable of training mind concentration is yoga. Yoga is part of Hindu philosophy, besides the teachings of yoga listed in the Patanjali Yogasutra are also found in Indian philosophy, Sad Darsana. Both in the teachings of Patanjali and Sad Darsana, both of them fully explain the eight stages of self-control called Astanggayoga. Astanggayoga consists of, yama, nyama, asanas, pranayama, pratyahara, darana, dyana and samadhi in Sarasvatī (2002).
\end{abstract}

Keywords: Yoga Asanas, Learning concentration

ABSTRAK:

Konsentrasi belajar berperan penting dalam proses pembelajaran. Akan tetapi dengan perkembangan Ilmu Pengetahuan dan Teknologi saat ini, konsentrasi belajar siswa tidak serta merta dapat dimiliki oleh siswa. Pemusatan pikiran adalah suatu keadaan belajar yang membutuhkan ketenangan, kenyamanan, perhatian seseorang dalam memahami isi pelajaran yang dihadapi. Bilamana seorang siswa tidak mampu memusatkan pikiran terhadap pelajaran yang sedang didapatkan, maka siswa tidak akan bisa berkonsentrasi, sehingga siswa akan mengalami kelupaan terhadap mata pelajaran yang sedang didapat. Salah satu pelatihan yang dianggap mampu untuk melatih pemusatan pikiran adalah yoga. Yoga merupakan bagian dari filsafat Hindu, ajaran yoga ini selain tercantum dalam Yogasutra Patanjali juga terdapat di dalam filsafat India yaitu Sad Darsana. Baik itu di dalam ajaran Patanjali maupun Sad Darsana, keduanya secara lengkap menjelaskan delapan tahapan pengendalian diri yang disebut Astanggayoga. Astanggayoga terdiri dari, yama, nyama, asanas, pranayama, pratyahara, darana, dyana dan Samadhi dalam Sarasvatī (2002).

Kata Kunci: Yoga Asanas, Konsentrasi Belajar

\section{PENDAHULUAN}

Modernisasi dan globalisasi adalah dua konsep yang sudah tidak asing lagi di dunia ilmu pengetahuan. Selain dalam ilmu pengetahuan, istilah modernisasi dan globalisasi ini juga berkembang dalam dunia pendidikan sekarang ini.

Perkembangan dunia pendidikan tidak terlepas dari pengaruh globalisasi yang memberikan dampak sangat luas. Sebagai contoh munculnya sifat-sifat individualistik, menurunnya etika ketimuran, menurunnya moralitas, dan turunnya konsentrasi belajar siswa.

Turunnya konsentrasi belajar siswa disebabkan oleh banyak faktor seperti tidak memiliki motivasi diri, suasana lingkungan belajar yang tidak kondusif, kondisi kesehatan siswa yang kurang baik, siswa merasa jenuh. Aspek konsentrasi belajar menurut Nugroho (2007) adalah 
motivasi, rasa kuatir, perasaan tertekan, gangguan pemikiran, gangguan kepanikan, kesiapan belajar dan pemusatan pikiran.

Pemusatan pikiran adalah suatu keadaan belajar yang membutuhkan ketenangan, kenyamanan, perhatian seseorang dalam memahami isi pelajaran yang dihadapi. Bilamana seoran g siswa tidak mampu memusatkan pikiran terhadap pelajaran yang sedang didapatkan, maka siswa tidak akan bisa berkonsentrasi, sehingga siswa akan mengalami kelupaan terhadap mata pelajaran yang sedang didapat.

Salah satu pelatihan yang dianggap mampu untuk melatih pemusatan pikiran adalah yoga. Yoga merupakan bagian dari filsafat Hindu, ajaran yoga ini selain tercantum dalam Yogasutra Patanjali juga terdapat di dalam filsafat India yaitu Sad Darsana. Baik itu di dalam ajaran Patanjali maupun Sad Darsana, keduanya secara lengkap menjelaskan delapan tahapan pengendalian diri yang disebut Astanggayoga. Astanggayoga terdiri dari, yama, nyama, asanas, pranayama, pratyahara, darana, dyana dan Samadhi dalam Sarasvatī (2002).

\section{PEMBAHASAN}

\subsection{Yoga Asanas}

Istilah Yoga merupakan suatu istilah yang sudah tidak asing lagi bagi masyarakat pemeluk agama Hindu. Beberapa kalangan masyarakat hanya memahami istilah yoga sebagai aktivitas tubuh dalam suatu gerakan, posisi, atau pose tertentu. Pemahaman seperti tersebut tidaklah salah, namun tidak mencakup pengertian Yoga secara keseluruhan, pemahaman tersebut hanya mengandung beberapa unsur kebenaran, karena yang mereka maksudkan adalah āsanas yang merupakan salah satu unsur atau bagian dari Yoga.

Di samping itu juga, beberapa kalangan masyarakat memahami Yoga sebagai suatu aktivitas perenungan atau kontemplasi dengan mencari tempat-tempat sepi dan angker, untuk memperoleh kekuatan kesaktian.

Menurut maha Rsi Patanjali dalam kitab Yoga Sutra, istilah Yoga dirangkum dalam sebuah kalimat pendek atau sutra sebagai berikut: Yogas Citta Vrtti Nirodhah (Yoga Sutra I.2) artinya: Yoga adalah pengekangan benih-benih pikiran (citta) dari pengambilan berbagai wujud (perubahan; wrtti) (Saraswati, 2005: 279). Berdasarkan pengertian tersebut, Yoga merupakan sebuah aktivitas mental atau pikiran untuk mengendalikan pikiran atau pun benih-benih pikiran dari pengambilan berbagai wujud atau perubahan-perubahan yang timbul dari pikiran akibat dari kontak dengan panca indria. Untuk dapat mencapai keadaan tersebut, lebih lanjut Maha Rsi Patanjali memberikan rumusan sebagai suatu bentuk disiplin, untuk mencapai hakekat Yoga yang sesungguhnya. Adapun rumusan yang dimaksudkan adalah sebagai berikut: yama niyamāsana prānayāma pratyāhāra dhāranā dhyāna samādha yo 'stāw angāni (Yoga Sutra II.29) artinya: Pengekangan diri (yama), kepatuhan yang mantap (niyama), sikap badan (āsana), pengaturan pernafasan (prānayāma), penyaluran (pratyāhāra), pemusatan (konsentrasi; dhāranā), perenungan (dhyāna), penyerapan (samādhi) semua ini adalah bagian (dari disiplin diri dari Yoga) (Saraswati, 2005: 290).

Asanas berasal dari bahasa sanskerta yaitu Asana yang artinya sikap badan atau gerakan. Asana juga berarti suatu keadaan tubuh yang tetap mantap, tenang, santai dan nyaman baik secara fisik maupun secara mental. Dalam tulisan kuno mengenai Yoga oleh Patanjali yang disebut Yoga Sutra, ada definisi singkat tentang Yoga Asana yaitu Sthiram Sukham Asanam yang artinya bahwa keadaan yang nyaman dan mantap.

\subsection{Konsentrasi Belajar}

Konsentrasi adalah pemusatan atau pengarahan (perhatiannya ke pekerjaannya atau aktivitasnya) (Homby dan Siswoyo, 1993). Menurut Slameto (2003) konsentrasi merupakan 
pemusatan pikiran terhadap suatu hal dengan menyampingkan semua hal lainnya yang tidak berhubungan. Dalam belajar konsentrasi berarti pemusatan pikiran terhadap mata pelajaran dengan menyampingkan semua hal yang tidak berhubungan dengan pelajaran.

Hendrata (2007) berpendapat konsentrasi adalah sumber kekuatan pikiran dan bekerja berdasarkan daya ingat dan lupa dimana pikiran tidak dapat bekerja untuk lupa dan ingat dalam waktu bersamaan. Apabila konsentrasi seseorang mulai lemah maka cenderung mudah melupakan suatu hal dan sebaliknya apabila konsentrasi masih cukup kuat maka akan dapat mengingat dalam waktu yang lama.

Djmarah (2008) mengungkapkan bahwa konsentrasi adalah pemusatan fungsi jiwa terhadap suatu objek seperti konsentrasi pikiran, perhatian dan sebagianya. Dalam belajar dibutuhkan konsentrasi dalam bentuk perhatian yang terpusat pada suatu pelajaran. Maka dari itu konsentrasi merupakan salah satu aspek yang mendukung siswa untuk mencapai prestasi yang baik dan apabila konsentrasi ini berkurang maka dalam mengikuti pelajaran di kelas maupun belajar secara pribadi akan terganggu.

Saraswati (2005: 220, 223) mengungkapkan bagian astangga yoga yang keenam adalah dhārana yang berarti pemusatan pikiran atau konsentrasi. Konsentrasi mental (pemusatan pikiran) dalam yoga dan sikap-sikap dalam yoga membantu siswa dalam memproduksi zat-zat kimia oleh kelenjar-kelenjar dan dengan demikian menghasilkan akibat-akibat yang dapat dilihat dengan konsentrasi mental dapat menghasilkan perasaan supra berupa rabaan, rasa, bunyi, warna, bau, dll.

Dapat disimpulkan bahwa konsentrasi baik dari pengertian yoga maupun umum artinya pemusatan pikiran terhadap suatu objek dan jika dikaitkan dengan proses belajar mengajar konsentrasi merupakan pemusatan pikiran terhadap mata pelajaran yang sedang didapatkan.

\subsection{Yoga Asanas Sebagai Penunjang Konsentrasi Belajar Siswa}

Ada berbagai macam jenis āsana dalam ajaran yoga yang mempunyai manfaat dan kegunaan masing-masing termasuk untuk melatih konsentrasi, diantaranya:

\section{Tadāsana (Sikap Pohon Palem)}

Berdiri tegak dengan kedua kaki direnggangkan satu kepal. Letakkan kedua tangan di depan pusar, angkat kedua lengan keatas kepala dan kedua tangan bisa dicakupkan atau kaitkan jari-jari tangan dan hadapkan telapak tangan keatas. Pandangan bisa lurus kedepan, pandang satu titik agar tidak goyah atau memandang ke jari-jari tangan. Angkat kedua tumit dan rasakan seolah-olah seluruh badan ditarik ke atas, ketika sudah merasa tidak kuat turunkan posisi tumit dan turunkan kedua tangan keposisi semula.

\section{Nafas:}

Ketika mengankat tangan keatas lakukan penarikan nafas, ketika tangan sudah berada diatas dan pandangan sudah terfokus pada satu titik,nafas ditahan, dan hembuskan kembali ketika menurunkan kedua tangan.

\section{Manfaat:}

Dalam (Saraswati, 2002: 114-115) manfaat dari gerakan ini melatih atau meningkatkan konsentrasi. Memperkuat otot-otot perut dan merenggangkan usus. Membersihkan sumbatan syaraf-syaraf tulang berlakang pada persendian yang muncul dari tulang belakang.

Sikap pohon palem mampu untuk meningkatkan konsentrasi siswa jikalau sikap tersebut dilakukan dengan sungguh-sungguh dan dilakukan secara disiplin.

\section{Trikoṇāsana (Sikap Segitiga)}

Berdiri tegak dengan kedua kaki dibuka dua kali lebar bahu. Tekuk tangan kanan dan letakkan 
dipinggang, tangan kiri diluruskan kedepan. Naikkan tangan kiri tempelkan pada telinga kiri lalu tekuk badan kesebelah kanan. Usahakan tangan kanannya menempel pada kaki sebelah kiri. Pandangan fokus ke siku tangan kiri. dan jika sudah dirasa cukup kembali pandang kedepan dan angkat badan secara perlahan.

\section{Nafas:}

Tarik nafas ketika mengangkat tangan, tahan nafas ketika menekuk pinggang ke kiri ataupun ke kanan, dan hembuskan nafas ketika mengembalikan posisi badan.

\section{Manfaat:}

Dalam (Saraswati, 2002: 124) āsana ini menguatkan otot-otot dalam tulang punggung antara tulang belakang bagian atas dengan kedua bilah bahu, dan menguatkan dada serta leher. Melatih konsentrasi dan āsana ini baik terutama bagi anak-anak, atau anak muda yaitu pada masamasa pertumbuhan.

Dilihat dari penjelasan diatas bahwa āsana ini bermanfaat untuk perbaikan tulang belakang, pertumbuhan serta meningkatkan konsentrasi.

\section{Natarāja āsana (Sikap Dewa Siwa)}

Berdiri tegak, letakkan tangan kiri di depan dada dengan ibu jari dan telunjuk disatukan (jnana mudra). Pegang pergelangan kaki kanan dengan menggunakan tangan kanan, tekuk kaki kanan ke belakang dan angkat kaki setinggi mungkin. Ulurkan tangan kiri ke atas atau sejajar dengan badan. Fokuskan pandangan ke daerah jari tangan yang membentuk jnana mudra. Lakukan secara bergantian.

\section{Nafas:}

Tarik nafas seiring dengan merentangkan tangan ke atas atau ke depan, tahan nafas ketika menahan posisi yang sudah sempurna dan hembuskan nafas seiring dengan menurunkan tangan dan kaki.

\section{Manfaat:}

Dalam (Saraswati, 2002: 261) manfaat dari āsana diatas adalah untuk menyeimbangkan jaringan syaraf, membantu dalam pengendalian jasmani dan melatih konsentrasi mental serta membuat kedua kaki lemas.

Dari penjelasan diatas dapat disimpulkan bahwa āsana tersebut bermanfaat untuk meningkatkan konsentrasi dan membuat otot kaki dan tangan menjadi lemas.

\section{Natavara āsana (Sikap Dewa Krsna)}

Berdiri tegak, letakkan kaki kanan kesebelah kaki kiri dengan jari-jarinya sedikit diatas tanah dan telapak kaki hampir tegak lurus. Sandarkan betis kanan pada tulang kering kaki kiri. Angkat kedua tangan seolah-olah sedang memainkan seruling. Pandangan kedepan atau kedua mata bisa dipejamkan. Lakukan secara bergantian.

\section{Nafas:}

Tarik nafas ketika mengangkat kedua tangan, tahan nafas ketika posisi sudah sempurna dan hembuskan nafas ketika menurunkan tangan dan melepaskan kaitan kaki.

\section{Manfaat:}

Dalam (Saraswati, 2002: 260) manfaat dari āsana diatas adalah untuk mengontrol syaraf-syaraf, membantu dalam meningkatkan konsentrasi dan merupakan suatu sikap pendahulu yang baik untuk meditasi.

Dari penjelasan diatas dapat disimpulkan bahwa āsana tersebut bermanfaat untuk memperlancar peredaran darah untuk menambah ketenangan dan untuk meningkatkan konsentrasi.

\section{Gomukhāsana (Sikap Muka Sapi)}

Ambil posisi duduk, rentangkan kedua kaki. Lipat kaki kiri dan letakkan tumit di samping pantat kanan. Lipat kaki kanan diatas ujung kaki kiri sehingga tumit kanan berada di atas tanah di samping paha kiri. Kedua lutut letaknya harus bertumpuk satu dengan yang lainnya. Letakkan 
lengan kiri di belakang punggung dan lengan kanan diatas bahu kanan. Kaitkan jari-jari tangan di belakang punggung. Buat tubuh tegak, pandang siku sebelah kanan. Ulangi proses tersebut pada sisi lainnya.

\section{Nafas:}

Tarik nafas ketika melihat siku, dan hembuskan nafas ketika menurunkan tangan.

\section{Manfaat:}

Dalam (Saraswati, 2002: 190) manfaat āsana diatas adalah membantu menghilangkan diabetes, sakit punggung, bahu dan leher yang kaku dan berbagai penyakit seksual lainnya. Merangsang ginjal, meringankan pegal pada pinggang dan rematik serta menguatkan dada meningkatkan konsentrasi.

Dari penjelasan diatas dapat disimpulkan bahwa āsana diatas bermanfaat unuk menghilangkan sakit punggung, karena memang punggung harus diluruskan agar tangannya bisa terkait dibelakang serta mampu untuk meningkatkan konsentrasi.

\section{Pada Angusthāsana (Sikap Ujung Jari Kaki)}

Ambil posisi jongkok, angkat kedua tumit, turunkan kedua lutut sehingga paha mendatar. Satu kaki diletakkan di atas paha yang berlawanan. Tumit dari kaki yang menyangga tubuh harus menekan ke arah selangkangan. Perlahan seimbangkan badan, lalu kedua telapak tangan diletakkan rapat di depan dada. Pandang lurus ke depan, pikiran dipusatkan pada satu titik agar seimbang. Lakukan secara bergantian.

\section{Nafas:}

Tarik nafas ketika mengangkat tangan, tahan nafas ketika kedua tangan sudah diletakkan di depan dada, dan hembuskan nafas sembari menurunkan kedua tangan.

\section{Manfaat:}

Dalam (Saraswati, 2002: 269) āsana ini bermanfaat terutama bagi pelajar atau siswa, karena mampu meningkatkan konsentrasi. Selain itu āsana ini juga berfungsi untuk mengatur sistem seksual, membantu menguatkan jari-jari kaki serta pergelangan kaki.

Dari pemaparan diatas dapat disimpulkan bahwa āsana tersebut baik sekali jika dilatih untuk siswa atau pelajar karena mampu untuk meningkatkan konsentrasi serta memperkuat jarijari kaki.

\section{Ardha Matsyendrāsana (Sikap Setengah Memutar Tulang Belakang)}

Duduk dengan kedua kaki lurus di depan tubuh. Kaki kanan ditekuk datar diatas lantai di luar lutut kiri. Tekuk kaki kiri ke kanan. Dan letakkan tumit kiri pada pantat kanan. Lengan kiri diletakkan di luar kaki kanan, dan dengan tangan kiri tarik kaki atau pergelangan kaki kanan. Lutut kanan harus sedekat mungkin dengan ketiak kiri. Putar tubuh ke kanan, letakkan lengan kanan di belakang punggung. Putar punggung, kemudian leher sejauh mungkin tanpa ketegangan. Pandangan lurus ke belakang dan fokuskan pada satu titik. Tetap pada sikap akhir selama beberapa detik kemudian secara perlahan kembalikan keposisi awal. Rubah posisi kaki dan ulangi pada bagian tubuh lainnya.

\section{Nafas:}

Nafas dihembuskan saat memutar tubuh. Bernafas sedalam mungkin tanpa ketegangan pada sikap akhir, tarik nafas ketika kembali keposisi awal.

\section{Manfaat:}

Dalam (Saraswati, 2002: 211) āsana diatas bermanfaat untuk menyelaraskan syaraf-syaraf tulang belakang, membuat otot-otot punggung lemas dan mengendurkan tulang belakang. Memijat organ-organ perut, dengan cara demikian menghilangkan berbagai penyakit pencernaan. Membantu mengatur keluarnya adrenalin dari 
kelenjar, kelenjar adrenalin serta meningkatkan konsentrasi.

Dari pemaparan tersebut āsana diatas bermanfaat untuk memperbaiki tulang belakang yang rusak, melancarkan pencernaan dan meningkatkan konsentrasi.

\section{Merudandāsana (Sikap Tulang Belakang)}

Ambil posisi duduk. Tekuk kedua kaki pada lutut dan letakkan telapak kaki di lantai di depan pantat. Kedua kaki harus renggang kira-kira setengah meter. Tarik ibu jari kaki dan kendorkan seluruh tubuh. Secara perlahan miringkan tubuh ke belakang dan luruskan kedua kaki. Kedua lengan dan kaki harus lurus dan renggang selebar mungkin. Pandangan lurus ke depan, dan pertahankan posisi tersebut selama beberapa detik.

\section{Nafas:}

Tarik nafas ketika duduk. Tahan nafas di dalam perut saat merentangkan kedua kaki. Hermbuskan nafas setelah selesai.

\section{Manfaat:}

Menurut Arimbawa dalam (Wawancara, 03 Juni 2016) āsana diatas bermanfaat untuk menyeimbangkan tubuh, memperbaiki otot kaki dan tangar, melueruskan tulang belakang dan melatih konsentrasi.

Yang diungkapkan pula dalam (Saraswati, 2002: 255) bahwa āsana tersebut bermanfaat untuk mengaktifkan organ-organ perut, terutama hati dan menguatkan otot-otot perut. Membantu menghilangkan cacing usus, merangsang gerak peristaltik (umbai cacing) usus dan menyeimbangkan seluruh daerah perut. Menyeimbangkan keseimbangan tubuh dan konsentrasi.

Dari penjelasan tersebut dapat disimpulkan bahwa āsana diatas bermanfaat untuk memperbaiki organ perut, menyelaraskan tubuh, menyeimbangkan tubuh dan meningkatkan konsentrasi.
Setiap asanas yang dijelaskan diatas mempunyai manfaat untuk menyeimbangkan tubuh serta pikiran dan melatih konsentrasi, jika dilakukan secara bertahap dan tekun tentu akan memperoleh manfaat untuk menunjang konsentrasi belajar siswa.

\section{SIMPULAN}

Yoga merupakan salah satu cara untuk mengendalikan arus globalisasi yang semakin bergulir, dengan dilakukannya yoga yang tekun diharapkan mampu untuk mencapai tujuan yang diperlukan di era ini. Latihan yoga asanas tidak hanya berdampak positif bagi fisik, tetapi juga bermanfaat bagi pikiran dan jiwa, termasuk dalam penunjang konsentrasi belajar siswa. 